\title{
A First Step Towards Synthesising Rubrics and Video for the Formative Assessment of Complex Skills
}

Citation for published version (APA):

Ackermans, K., Rusman, E., Brand-Gruwel, S., \& Specht, M. (2017). A First Step Towards Synthesising Rubrics and Video for the Formative Assessment of Complex Skills. In Technology Enhanced Assessment: 19th International Conference, TEA 2016, Tallinn, Estonia, October 5-6, 2016, Revised Selected Papers (Vol. 653, pp. 1-10). Springer International Publishing AG. Communications in Computer and Information Science Vol. 653 https://doi.org/10.1007/978-3-319-57744-9_1

\section{DOI:}

10.1007/978-3-319-57744-9_1

Document status and date:

Published: 01/01/2017

Document Version:

Peer reviewed version

\section{Document license:}

CC BY

Please check the document version of this publication:

- A submitted manuscript is the version of the article upon submission and before peer-review. There can be important differences between the submitted version and the official published version of record. People interested in the research are advised to contact the author for the final version of the publication, or visit the DOI to the publisher's website.

- The final author version and the galley proof are versions of the publication after peer review.

- The final published version features the final layout of the paper including the volume, issue and page numbers.

Link to publication

\section{General rights}

Copyright and moral rights for the publications made accessible in the public portal are retained by the authors and/or other copyright owners and it is a condition of accessing publications that users recognise and abide by the legal requirements associated with these rights.

- Users may download and print one copy of any publication from the public portal for the purpose of private study or research.

- You may not further distribute the material or use it for any profit-making activity or commercial gain

- You may freely distribute the URL identifying the publication in the public portal.

If the publication is distributed under the terms of Article 25fa of the Dutch Copyright Act, indicated by the "Taverne" license above, please follow below link for the End User Agreement:

https://www.ou.nl/taverne-agreement

Take down policy

If you believe that this document breaches copyright please contact us at:

pure-support@ou.nl

providing details and we will investigate your claim.

Downloaded from https://research.ou.nl/ on date: 26 Apr. 2023 


\title{
A First Step Towards Synthesiz- ing Rubrics and Video for the Formative Assessment of Com- plex Skills
}

\begin{abstract}
The performance objectives used for the formative assessment of complex skills are generally set through text-based analytic rubrics[1]. Moreover, video modeling examples are a widely applied method of observational learning, providing students with context-rich modeling examples of complex skills that act as an analogy for problem solving [1]. The purpose of this theoretical paper is to synthesize the components of video modeling and rubrics to support the formative assessment of complex skills. Based on theory, we argue that application of the developed Video Enhanced Rubrics (VER) fosters learners' development of mental models, quality of provided feedback by various actors and finally, the learners mastery of complex skills.
\end{abstract}

Keywords. video rubrics $($ formative) assessment $\cdot$ complex skills·mental models

\section{Introduction}

Students in Dutch secondary education follow a standardized curriculum in preparation for further study at the vocational or university level. The standardized curriculum currently mainly tests the knowledge of a student, as opposed to the ability of the student to construct and apply knowledge and to master skills. However, to prepare learners for further education, learners need to manage their learning and be able to construct knowledge and master skills [2]. It is important to provide learners with the insight in how to master complex skills, if we expect them to assess and develop complex skills that prepare them for further education. However, several schools in Dutch primary and secondary education have difficulty implementing and evaluating a set of generic complex skills that are beneficial for the learners development also known as $21^{\text {st }}$ 
century skills [3]. A recent study on the Dutch educational system concludes that current implementations for teaching complex skills lack efficiency, explicitness and structure [4]. Reasons for this can found in the individual nature of the school's implementations, resulting in a lack of coordinated and systematic implementation [4]. In the assessment of complex skills, rubrics offer teachers a practical and systematical method to analyze the learners performance. Rubrics are effective in assessment settings because they provide transparency of grading criteria to learners [5]. For this paper, the term rubrics is used for text-based analytic rubrics. Rubrics provide a detailed description of each level of mastery of a complex skill. This detailed description provides transparent communication of the assessment criteria. The inherent complexity of complex skills can be analyzed through the use of rubrics, making them valuable to teachers. To gain insight into the definition of complex skills, we highlight several characteristics. One of the main characteristics of complex skills is that they are hard to learn, requiring an estimated five hundred hours to acquire [6]. Complex skills are skills that are comprised of a set of constituent skills which require conscious processing [7]. A single skill, such as typing, differs in complexity from a complex skill such as giving a presentation. Giving a presentation is comprised out of several constituent skills, such as using presentation software, communication and use of information. Textual analytic rubrics describe the inherent complexity of complex skills, but do not provide a modeling example to contextualize the skill and build a complete mental model [1]. The focus of this paper is on the synthesis of video and rubrics, that fosters the learners' development of mental models, feedback quality and mastery of complex skills.

\subsection{Problem definition}

Analytic rubrics are one of the main instruments used for the (formative) assessment of complex skills. However, rubrics have several deficiencies we should take into account. Firstly, complex skills are comprised of several constituent skills, generally identified by professionals. Constituent skills must be seen as aspects of the complex skill because a complex skill is more than the sum of its aspects [6]. By defining relative proficiency of a complex skill, a rubric describes the quality of the learner's performance in terms of skills mastery levels. However, rubrics provide a purely textual framework to assess the learner's relative proficiency of complex skill aspects. The resulting assessment on aspect-level 
provides an incomplete and moderately reliable assessment of complex skill [8]. In summary, fully assessing complex skills requires an assessment tool with both the ability to assess progress on constituent skill level and assess progress of the coordination, combination and integration of these constituent skills, forming a complete complex skill $[1,7]$. Secondly, constituent skills are formulated as performance objectives in the 4 Component Instructional Design (4CID) method. Using rubrics, the four elements of a performance objective are described on a textual level. These elements are the 1)tools 2)conditions 3)standards and 4)action the learner should perform to meet the performance objective [6]. Learners use the performance objectives found in rubrics as a systematic approach to problem solving, enabling low-achieving learners to strategically reach a passing grade $[9,10]$. However, according to the 4CID model a systematic approach to problem solving should not be provided without illustrating relevant examples because a mental model is not only built on the general, abstract knowledge of a skill. A mental model is also built on the concrete case of a professionals' consciously controlled mental processes when applying a complex skill. These concrete cases can be visualized in a video modeling example. Thirdly, the textual form of rubrics inherently lack contextual and dynamic information need by the learner to provide the textual assessment criteria with context and procedural information [11]. In summary, imbedding video modeling examples in textual rubrics may create a more complete complex skill description, and secondly may provide a more complete mental model of the complex skill. The accuracy of the created mental model is of importance, as higher accuracy relates to higher performance of the learners' complex skills [12]. In summary, we expect video may supplement supportive information and contextualized illustration to textual analytic rubrics. The proposed benefits can be an addition to the transparency, validity, performance and feedback quality's provided by rubrics [1, 13$18]$.

\section{Theoretical framework}

Having proposed the introduction of video into the (formative)assessment of complex skills through rubrics, we here explore the theoretical arguments for its effectiveness.

First, we need to be aware of the effects of rubrics and their influence on complex skill assessment and development. The transparent grading 
criteria found in rubrics is a main contributing factor to their quality and effectiveness, positively influencing the learners' performance and the assessment validity of rubrics [13-18]. From a learners standpoint, the transparency of rubrics fosters feedback and allows low achieving students to strategically reach a passing grade by providing insight in the minimum requirements per constituent skill $[9,10]$. Furthermore, the transparent assessment criteria found in rubrics reduces anxiety in learners [19-21]. Another aspect contributing to the transparency of rubrics is the increased accuracy, validity and reliability of the self- and peer assessment of complex skills $[5,8,22]$. One of the methods used to assess the mental model creation of a complex skill is the creation of a contextual map by the learner. By fostering the representation of knowledge through clear textual descriptions, rubrics foster the quality of the learners' conceptual maps [5]. Concluding, the transparent skill mastery levels provided by rubrics may foster insight in, feedback on and (formative) assessment of complex skills.

Secondly, by implementing video we are proposing the integration of moving images and audio to textual rubrics. The dynamic superiority effect describes the advantages of video over static visual images [11]. This theory states that moving pictures increase the learners' performance because they are remembered better, contain more information, provide more cues to aid retrieval from long term memory, attract more attention from the learner and increase learner engagement [11]. Specifically of interest for this paper, the dynamic superiority effect also states that the encoding of a video scene involves extraction of semantic and dynamic information, thereby supplementing the rubrics lack of contextual and dynamic information. In the retrieval of the scene from long term memory, the encoded process is simulated by the learner. This provides a richer mental model of the complex skill through the visualization of the professionals' consciously controlled mental processes when applying a complex skill $[1,11]$. As mentioned in the problem definition, a richer mental model relates to higher performance of the learners' complex skills [12]. One aspect of influence on the learning outcomes is the demonstrated mastery level of the provided modeling example. In contradiction to the model-observer similarity (MOS) principle, adults are more effective video models then peers [23]. Specifically of interest for the development of the complex skill of collaboration, Kim and MacDonough [24] report increased collaborative learning interaction through the implementation of video. The complex skill of presentation has been 
studied by De Grez et. Al [25], finding learning through video to be more effective then extensive practice in the performance of presentations skills. Concluding, video provides contextual and dynamic information relevant for a complex skill, potentially leading to a richer mental model. However, to benefit from these advantages it is important to specify design considerations behind the combination of video and rubrics.

Thirdly, we focus on the shared aspects of video and rubrics to identify possible overlap. Both rubrics and video have been shown to foster selfassessment, self-regulatory skills and self-efficacy [5, 14, 17, 19, 26-31]. More importantly for this paper, self-regulated learning and self-efficacy act as a motivational predictor of performance on complex tasks and its constituent processes, such as search, information processing and memory processes that affect learning $[29,32,33]$. Specifically for the development of the complex skill of presenting, De Grez [33] stresses the importance of self-regulated learning as he found significantly increased learning gains as a result of implementing 'self-generated focused learning goals'. Moreover, the self-efficacy fostered by rubrics and video is critical in the development of presentation skills and can result in significant learning gains [34]. Concluding, we expect that the combined use of video and rubrics during the process of mastering a complex skill has a positive effect on self-regulated learning, which contributes to the performance of complex skills.

Forth, we subsequently examine theory to facilitate the synthesis of video and rubrics. The cognitive theory of multimedia learning (CTML) states that learners perform significantly better at the transfer of complex skills to new situations through a combined use of video and text, as opposed to text alone [35]. Within this theory, several principles for the effective implementation are described. The CTML principles aim to achieve three goals, namely to 1) reduce extraneous processing, 2) manage essential processing and 3) foster generative processing. Firstly, reducing extraneous load is achieved by lightening the load of the instruction. This can be done by excluding extraneous information, signaling, highlighting and avoiding redundancy. Secondly, the goal of managing essential processing is to limit the intrinsic load of the multimedia instruction to the learners' cognitive capacity, preventing essential cognitive overload. Relying mainly on the dual channel theory, this principle states that the visual channel is overloaded by simultaneously observing a video and reading on screen text [36]. This can be remedied by offload- 
ing the visual processing of the text to auditory processing by implementing narration. In order to achieve the final goal, fostering generative processing, the principles based on social cues are introduced. These principles activate a social response, increasing active cognitive processing. According to dual channel theory, active cognitive processing is essential in transferring information from the sensory memory into working memory. This fosters the quality of the learning outcome [37]. The stability of the multimedia effect has been recently studied, finding even a relatively simple multimedia implementation to be substantially and persistently more beneficial for retaining knowledge as compared to text alone [38]. However, the inherent complexity of a complex skill is challenging for the limited amount of working memory available to the learner. If the principles are implemented incorrectly, cognitive load is increased and mental model creation is limited, impacting performance [12]. To ensure effective implementation of video and text, Mayer's [35] CTML relies upon dual channel theory, cognitive load theory and the integrated theory of text and picture recognition. In addition to the principles of CTML, several studies have been done on partial aspects of instructional multimedia design. Eitel \& Scheiter's [39] review consisting of 42 studies regarding text and picture sequencing states that it is helpful for comprehension if the medium that contains the least complexity is presented first. Presenting the least complex medium (either text or picture) first may facilitate processing of the complex information presented in the second medium. These findings are in line with both CTML and the 4CID models. The CTML's pre-training principle states that simple information can be used to prime the learner for complex learning [35]. The 4CID model ranges task classes and supportive information from simple to complex to accommodate the sequencing principle [40].

\section{Conclusion.}

Analytic text-based analytic rubrics mainly contribute to the development of complex skill on a cognitive level, providing rich feedback, anxiety reducing transparency and performance enhancing insight into the performance levels of a complex skill. However, despite these advantages, three problems regarding formative assessment of complex skills using rubrics where defined. The first problem indicates the aspect level of rubric assessment and states that a complex skill is more than the sum of its identified aspects. We expect that the implementation of video 
combined with text-based rubrics will help to unify the individual aspects of rubrics into a complex skill. We expect video address the first and third problem by 'filling the gaps' between the individual aspects of the complex skill as video provides the learner with the opportunity to personally encode semantic and dynamic information from the modeling example of the complex skill, supplementing the information provided by the rubric and providing personalization. The second problem indicates that the information that a rubric provides when used as a systematic approach to problem solving by a learner is insufficient to form an accurate mental model of a complex skill. For a video to convey the appropriate information to form a mental model, it is of importance that the modeling example conveys the mastery of the complex task in such a manner that the learner can encode the rich mental model found in the actions of the professional performing the task. Concluding, we expect video to provide a rich enhancement to text-based rubrics for the specific use of (formatively) assessing complex skills. However, to ensure effective multimedia implementation it is of importance to adhere to CTML principles. In summary, we have taken a first step towards a synthesis of video and analytic text-based rubrics. We will focus further study on the development of design guidelines for effective implementation of video and analytic text-based rubrics for the (formative) assessment of complex skills in the XXXXX project. Information on the XXXXX project can be found on www.XXXXX.nl.

\section{Acknowledgement:}

We would like to gratefully acknowledge the contribution of the XXXXXX project, that is funded by the practice-oriented research programme of the Netherlands Initiative for Education Research (NRO), part of The Netherlands Organisation for Scientific Research (NWO).

\section{$5 \quad$ References}

1. Van Merriënboer JJG, Kirschner PA (2007) Ten Steps to Complex Learning. Lawrence Erlbaum Associates, Inc., New Jersey

2. Paavola S, Hakkarainen K (2005) The knowledge creation metaphor - An emergent epistemological approach to learning. Sci Educ 14:535-557. doi: 10.1007/s11191-004-5157-0

3. Rusman E, Martínez-Monés A, Boon J, et al (2014) Computer 
Assisted Assessment. Research into E-Assessment: International Conference, CAA 2014, Zeist, The Netherlands, June 30 -- July 1, 2014. Proceedings. In: Kalz M, Ras E (eds). Springer International Publishing, Cham, pp 1-14

4. Thijs A, Fisser P, Hoeven M van der (2014) 21E Eeuwse Vaardigheden in Het Curriculum Van Het Funderend Onderwijs. Slo 128.

5. Panadero E, Romero M (2014) To rubric or not to rubric? The effects of self-assessment on self-regulation, performance and self-efficacy. Assess Educ Princ Policy Pract 21:133-148. doi: 10.1080/0969594X.2013.877872

6. Janssen-Noordman AM, Van Merriënboer JJG (2002) Innovatief Onderwijs Ontwerpen. Wolters-Noordhoff, Groningen

7. Van Merriënboer JJG, Kester L (2005) The four-component instructional design model: Multimedia principles in environments for complex learning. Cambridge Handb .... doi: 10.1017/CBO9781139547369.007

8. Jonsson A, Svingby G (2007) The use of scoring rubrics: Reliability, validity and educational consequences. Educ Res Rev 2:130-144. doi: 10.1016/j.edurev.2007.05.002

9. Panadero E, Jonsson A (2013) The use of scoring rubrics for formative assessment purposes revisited: A review. Educ Res Rev 9:129-144. doi: 10.1016/j.edurev.2013.01.002

10. Mertler C (2001) Designing Scoring Rubrics for Your Classroom. Pract Assess Res Eval 7:1-10.

11. Matthews WJ, Buratto LG, Lamberts K (2010) Exploring the Memory Advantage for Moving Scenes. Vis cogn 18:1393-1420. doi: $10.1080 / 13506285.2010 .492706$

12. Gary M, Wood R (2005) Mental models, decision making and performance in complex tasks. Proc 23rd Int Conf ... 1-31.

13. Brookhart SM, Chen F (2014) The quality and effectiveness of descriptive rubrics. Educ Rev 1-26. doi: 10.1080/00131911.2014.929565

14. Reynolds-Keefer L (2010) Rubric-referenced assessment in teacher preparation: An opportunity to learn by using. Pract. Assessment, Res. Eval. 15:

15. Andrade HG (2001) The effects of instructional rubrics on learning to write. Curr Issues Educ 4:1-39.

16. Schamber JF, Mahoney SL (2006) Assesing and improving the 
quality of group critical thinking exhibited in the final projects of collaborative learning groups. J Gen Educ 55:103-137. doi: 10.1353/jge.2006.0025

17. Andrade H, Du Y (2005) Student perspectives on rubricreferenced assessment. Pract Assessment, Res Eval 10:1-11. doi: $10.1080 / 02602930801955986$

18. Good TL (1987) Two Decades of Research on Teacher Expectations: Findings and Future Directions. J Teach Educ 38:32-47. doi: 10.1177/002248718703800406

19. Panadero E, Tapia JA, Huertas JA (2012) Rubrics and selfassessment scripts effects on self-regulation, learning and selfefficacy in secondary education. Learn Individ Differ 22:806813. doi: 10.1016/j.lindif.2012.04.007

20. Wolters C a. (2003) Regulation of Motivation: Evaluating an Underemphasized Aspect of Self-Regulated Learning. Educ Psychol 38:189-205. doi: 10.1207/S15326985EP3804_1

21. Kuhl J (2000) A functional-design approach to motivation and self-regulation: The dynamics of personality systems and interactions. In: Handb. self-regulation. pp 111-169

22. Panadero E, Romero M, Strijbos JW (2013) The impact of a rubric and friendship on peer assessment: Effects on construct validity, performance, and perceptions of fairness and comfort. Stud Educ Eval 39:195-203. doi: 10.1016/j.stueduc.2013.10.005

23. Hoogerheide V, van Wermeskerken M, Loyens SMM, van Gog T (2016) Learning from video modeling examples: Content kept equal, adults are more effective models than peers. Learn Instr 44:22-30. doi: 10.1016/j.learninstruc.2016.02.004

24. Kim Y, McDonough K (2011) Using pretask modelling to encourage collaborative learning opportunities. Lang Teach Res 15:183-199. doi: 10.1177/1362168810388711

25. De Grez L, Valcke M, Roozen I (2014) The differential impact of observational learning and practice-based learning on the development of oral presentation skills in higher education. High Educ Res Dev 33:256-271. doi: 10.1080/07294360.2013.832155

26. Andrade H, Buff C, Terry J, et al (2009) Assessment-Driven Improvements in Middle School Students' Writing. Middle Sch J 40:4-12.

27. Brookhart SM, Chen F (2014) The quality and effectiveness of descriptive rubrics. Educ Rev 1911:1-26. doi: 
10.1080/00131911.2014.929565

28. Efklides A (2011) Interactions of Metacognition With Motivation and Affect in Self-Regulated Learning: The MASRL Model. Educ Psychol 46:6-25. doi: 10.1080/00461520.2011.538645

29. Schunk DH, Usher EL (2011) Assessing self-efficacy for selfregulated learning. In: Handb. self-regulation Learn. Perform. pp 282-297

30. Zimmerman BJ, Kitsantas A (2002) Acquiring writing revision and self-regulatory skill through observation and emulation. J Educ Psychol 94:660-668. doi: 10.1037/0022-0663.94.4.660

31. Van Dinther M, Dochy F, Segers M (2011) Factors affecting students' self-efficacy in higher education. Educ Res Rev 6:95108. doi: 10.1016/j.edurev.2010.10.003

32. Bandura A (1997) Theoretical perspectives. In: Self-efficacy Exerc. Control. p 604

33. De Grez L, Valcke M, Roozen I (2009) The impact of an innovative instructional intervention on the acquisition of oral presentation skills in higher education. Comput Educ 53:112-120. doi: 10.1016/j.compedu.2009.01.005

34. De Grez L, Valcke M, Roozen I (2009) The impact of goal orientation, self-reflection and personal characteristics on the acquisition of oral presentation skills. Eur J Psychol Educ 24:293306. doi: 10.1007/BF03174762

35. Mayer RE (2009) Multimedia learning (2nd ed.). Cambridge Univ Press. doi: 10.1007/s13398-014-0173-7.2

36. Paivio A (2008) Mental Representations: A dual coding approach. Ment Represent A Dual Coding Approach. doi: 10.1093/acprof:oso/9780195066661.001.0001

37. Ayres P (2015) State-of-the-Art Research into Multimedia Learning: A Commentary on Mayer's Handbook of Multimedia Learning. Appl Cogn Psychol 29:631-636. doi: 10.1002/acp.3142

38. Schweppe J, Eitel A, Rummer R (2015) The multimedia effect and its stability over time. Learn Instr 38:24-33. doi: 10.1016/j.learninstruc.2015.03.001

39. Eitel A, Scheiter K (2014) Picture or Text First? Explaining Sequence Effects when Learning with Pictures and Text. Educ Psychol Rev 153-180. doi: 10.1007/s10648-014-9264-4

40. Van Merriënboer JJG, Kester L (2014) the Four-Component Instructional Design Model: Multimedia Principles in 
Environment for Complex Learning. In: Mayer RE (ed) Cambridge Handb. Multimed. Learn. Cambridge University Press, pp 104-148 